IP Periodica Polytechnica Civil Engineering

60(3), pp. 379, 386 2016

DOI: $10.3311 /$ PPci.7605

Creative Commons Attribution (1)

RESEARCH ARTICLE

\section{Influence of Displacement Ductility on Concrete Contribution to Shear Strength}

\author{
Guray Arslan, Izzet Kiristioglu
}

Received 08-07-2014, revised 04-08-2015, accepted 11-01-2016

\begin{abstract}
Shear strength of reinforced concrete $(R C)$ members is composed of the contributions of the nominal shear strength provided by transverse reinforcement and concrete. The shear strength of RC members under cyclic lateral loading degrades much faster than the flexural strength. Based on this state, Seismic Codes tend to be excessively conservative and do not take into account the contribution of concrete in certain cases. The aim of this study is to investigate the influence of displacement ductility on concrete contribution to shear strength using finite element analyses (FEA). Based on the agreement between the FEA and experimental results selected from literature, a simple relation is proposed for the prediction of the concrete contribution to shear strength of $R C$ beams. The relation proposed takes into account a reduction of the normalized concrete contribution for increasing inelastic displacement demands, with a small residual strength at large ductility levels.
\end{abstract}

\section{Keywords}

reinforced concrete; beam; shear strength; displacement ductility

\section{Guray Arslan}

Faculty of Civil Engineering, Yıldız Technical University, Istanbul, Turkey

e-mail: aguray@yildiz.edu.tr

\section{Izzet Kiristioglu}

Faculty of Civil Engineering, Yıldız Technical University, Istanbul, Turkey e-mail: izzet86@gmail.com

\section{Introduction}

In order to prevent brittle shear failures at beam plastic hinge regions of earthquake-resistant structures, reinforced concrete (RC) members are designed to have shear strengths much greater than their flexural strengths. In addition, the shear strength of RC frame members degrades faster than the flexural strength does under cyclic loading [1]. Hence, Design Codes [2,-4] tend to be excessively conservative and the contribution of the concrete to the shear strength is either neglected or considered based on the enhancement in the flexural capacities of beam and column. A discontinuity exists between the two cases [5-7]. In order to replace this discontinuity with a smooth transition, various researches have been conducted. The shear degradation and the concrete contribution to the shear strength of RC members have been predicted as a function of ductility demand [8--16], deflection capacity [17] and drift ratio [18].

In this paper, the finite element analysis (FEA) results are compared with the results of experimental studies selected from literature, and it is observed that the lateral load-deflection curves of analysed beams are consistent with the experimental results. The beams were analyzed under monotonically increasing loads to investigate the influence of displacement ductility $\left(\mu_{\Delta}\right)$, which is defined in terms of maximum structural drift and the displacement corresponding to the idealized yield strength, on the normalized concrete contribution $\left(v_{c} / \sqrt{f_{c}}\right)$ of RC beams, where $v_{c}$ is the contribution of concrete to shear strength and $f_{c}$ is the compressive strength of concete. Simple relations for predicting the concrete contribution to shear strength and nominal shear strength of RC beams are proposed and compared with FEA results, four codes of practice and six equations proposed by different researchers.

\section{Shear strength of RC beams}

The following procedure outlines the guidelines recommended by ASCE-ACI426 [19] to determine the shear strength of RC members. The governing equation given by ACI318 [2] states that the shear strength must exceed the shear demand $\left(v_{u}\right)$ 


$$
\varphi v_{n} \geq v_{u}
$$

in which $\varphi$ is the shear strength reduction factor that is given as 0.75 in ACI318 [2]. In codes [2, 3, 20, 21] nominal shear strength of RC beams, $v_{n}$, consider contribution of concrete to shear strength, $v_{c}$, while the remainder is the contribution of transverse reinforcement to shear strength, $v_{s}$.

$$
v_{n}=v_{c}+v_{s}
$$

The contribution of transverse reinforcement to shear strength is obtained from the $45^{\circ}$ truss model and corresponds to yielding conditions of the reinforcement. In ACI318 [2], the contribution of concrete to shear strength taken as the shear strength corresponding to initiation of diagonal cracking, has been assessed empirically from experimental data and is typically simplified into the following:

$$
v_{c}=0.17 \sqrt{f_{c}}
$$

In TS500 [20], the contribution of concrete to shear strength based on the adaptation of ACI318 [2] Code simplified equation is given as:

$$
v_{c}=0.23 \sqrt{f_{c}}
$$

$\mathrm{RC}$ members under cyclic loading cannot maintain their properties such as stiffness and strength. The deterioration in their stiffness and strength leads to larger inelastic deformation demands and damage accumulation [22, 23]. Since the shear strength degradation is a complex phenomenon, most previous models are based on experimental data and field observations of earthquake-damaged buildings [24]. A number of models have been proposed to describe the interaction between flexural ductility and shear strength. The models considered in this study are given below.

The model proposed by Biskinis et al. [1] is employed in EC8-3 [25] for existing buildings. According to EC8-1 [26], in the case of elements characterized by a shear span ratio lower or equal to 2 , shear failure is controlled by diagonal compression and Eq. (5) is applied. In the case of shear span ratio higher than 2, shear failure is controlled by diagonal tension and Eqs. (6) (7) are applied. The cyclic shear strength decreases with the plastic part of ductility demand, expressed in terms of ductility factor of the transverse deflection of the shear span or of the chord rotation at member end: $\mu_{\Delta}^{p l}=\mu_{\Delta}-1$. The shear strength degradation caused by loads varies linearly between 0 and 5. $\mu_{\Delta}^{p l}$ equal to 5 is the value at which the maximum degradation is attained. According to EC8-3 [25], the shear capacity is the minimum value obtained by one of the models in Eqs. (5) and

$$
\begin{aligned}
& v_{\text {short }}=\frac{1}{\gamma_{e l}} \frac{4}{7}\left(1-0.02 \min \left(5 ; \mu_{\Delta}^{p l}\right)\right)\left(1+1.35 \frac{P}{A_{c} f_{c}}\right) . \\
& \left(1+0.45 \rho_{\text {tot }} 100\right) \sqrt{\min \left(f_{c} ; 40\right)} \sin 2 \delta
\end{aligned}
$$

$$
\begin{aligned}
& v_{\text {slender }}= \\
& \frac{1}{\gamma_{e l}}\left[\frac{h-x}{2-L_{v}} \min \left(P ; 0.55 A_{c} f_{c}\right)+\left(1-0.05 \min \left(5 ; \mu_{\Delta}^{p l}\right)\right) .\right. \\
& \left.\left[0.16 \max \left(0.5 ; 100 \rho_{t o t}\right)\left(1-0.16 \min \left(5 ; \frac{L_{v}}{h}\right)\right) \sqrt{f_{c}}+v_{s}\right]\right] \\
& v_{s}=\left(1-0.05 \min \left(5 ; \mu_{\Delta}^{p l}\right)\right)\left(\rho_{w} f_{y w}\right)
\end{aligned}
$$

In which $\gamma_{e l}$ is equal to 1.15 for primary seismic elements and 1.0 for secondary seismic elements, $\rho_{t o t}$ is the total longitudinal reinforcement ratio, $h$ is the depth of cross-section, $L_{v}$ is the ratio moment/shear at the end section, $P$ is the compressive axial load, $A_{c}$ is the cross-section area, taken as being equal to $b_{w} d$ for a cross-section with a rectangular web of width $b_{w}$ and structural depth $d, \delta$ is the angle between the diagonal and the axis of the column, $x$ is the compression zone depth, $\rho_{w}$ is the transverse reinforcement ratio and $f_{y w}$ is the yield stress of the transverse reinforcement.

Aschheim and Moehle [9] proposed that the concrete contribution to the shear strength of an RC column decays when the displacement ductility demand increases, as follows:

$$
v_{c}=0.3\left(k+\frac{P}{13.8 A_{g}}\right) \sqrt{f_{c}}
$$

in which, $k$ includes the effect of displacement ductility $\left(k=\left(4-\mu_{\Delta}\right) / 3\right)$ and cannot be smaller than 0 and larger than 1.0 and $A_{g}$ is the gross section area. This model was adopted in FEMA 273 [14].

Priestley et al. [10] have proposed a relationship for predicting concrete contribution to shear strength that is expressed as a function of displacement demand,

$$
v_{c}=k \sqrt{f_{c}}
$$

in which $k$ depends on $\mu_{\Delta}$, which reduces from 0.29 in $\mathrm{MPa}$ units for $\mu_{\Delta} \leq 2.0$ to 0.10 in MPa units for $\mu_{\Delta} \leq 4.0$.

Perez and Pantazopoulou [27] proposed the parametric relationship between shear strength and deformation demand through a nonlinear analytical model of cyclic plane stress states in RC. The concrete contribution to shear strength is defined as

$$
v_{c}=\frac{\alpha \rho_{s}}{\left(1+\mu_{\Delta}\right)} \sqrt{f_{c}}\left(1-\beta \frac{n}{\sqrt{f_{c}}}\right)
$$

The constant $\alpha$ and $\beta$ can be taken as 37 and 7.6, respectively. $\rho_{s}$ and $n$ are the amount of transverse reinforcement ratio and influence of applied uniaxial stress, respectively. 
In FEMA356 [28], the flexural strength of RC members is calculated for expected material strengths. The concrete contribution to shear strength is defined as

$$
v_{c}=\lambda k_{2}\left(\frac{0.5 \sqrt{f_{c}}}{M / V d} \sqrt{1+\frac{P}{0.5 \sqrt{f_{c}} A_{g}}}\right)
$$

in which $k_{2}=1.0$ for $\mu_{\Delta} \leq 2.0$ and $k_{2}=0.7$ for $\mu_{\Delta} \geq 4.0$, with linear variation between these limits; $\lambda=1.0$ for normal weight concrete; $M$ and $V$ are the moment and shear at section of maximum moment; and the value of $M / V d$ is limited to $2 \leq$ $a / d \leq 3$.

Sezen and Moehle [15] proposed a concrete contribution to shear strength equation for lightly RC members accounting for apparent strength degradation associated with flexural yielding as

$$
v_{c}=k\left(\frac{0.5 \sqrt{f_{c}}}{a / d} \sqrt{1+\frac{P}{0.5 \sqrt{f_{c}} A_{g}}}\right)
$$

The value of $a / d$ is limited to $2 \leq a / d \leq 4 ; k=1$ for $\mu_{\Delta} \leq 2.0$ and $k=0.7$ for $\mu_{\Delta} \geq 6.0$, with linear variation between these limits.

Kowalsky and Priestley [29] proposed a revised version of UCSD (University of California, San Diego) shear model, where the reduction in the concrete contribution to the shear strength due to the larger column aspect ratio and the effect of longitudinal steel ratio $\left(\rho_{l}\right)$ are considered. Thus, $v_{c}$ is defined as:

$$
v_{c}=\alpha \beta \gamma \sqrt{f_{c}}
$$

in which $\alpha$ includes the effect of aspect ratio $(\alpha=3-M / V d)$ and cannot be smaller than 1.0 and larger than 1.5, and $\beta$ accounts for the effect of longitudinal reinforcement $\left(\beta=0.5+20 \rho_{l}\right)$. The strength degradation factor, $\gamma$, is reduced at relatively large values of displacement ductility and cannot be smaller than 0.05 and larger than 0.29 . It is indicated that the shear strength degradation due to increasing ductility is mostly because aggregate interlocking reduces as crack widths become wider.

Howser et al. [16] proposed a model based on Priestley et al. [10] approach. The concrete contribution to shear strength is defined as

$$
v_{c}=k \sqrt{f_{c}}
$$

in which $k$ is the factor for influence of flexural ductility. $k=$ 0.29 for $\mu_{\Delta}<2.0 ; k=0.29-0.12\left(\mu_{\Delta}-2\right)$ for $2 \leq \mu_{\Delta}<r$; $k=0.53-0.095 r-0.025 \mu_{\Delta}$ for $r \leq \mu_{\Delta} \leq q$; and $k=$ $0.53-0.095 r-0.025 q$ for $\mu_{\Delta}>q$; $r$ is the flexural ductility at the point where the slope changes and $q$ is the flexural ductility at the point where the slope changes to zero. $q=-144 \rho_{t}+$ 5.3 and $r=-13300 \rho_{s}^{2}+242 \rho_{s}+2.8$ for $\rho_{s} \leq 0.01, q=$ $r=3.85$ for $\rho_{s}>0.01, \rho_{s}$ is the volumetric ratio of transverse reinforcement.

\section{Beam properties}

Ma et al. [30] tested RC cantilever beams under cyclic loading to study the inelastic behavior of critical regions. Rashid and Mansur [31] tested RC beams under monotonically increasing loading to evaluate the implications of using high-strength concrete. The beams (Figure[1), tested by Ma et al. [30] and Rashid and Mansur [31], were analyzed here using three-dimensional nonlinear FEA.

The properties of the RC beams are given in Table 1, $a / d$ is the span-to-depth ratio, which is in between 2.75 and 4.46; $n_{s}, \varphi_{s w}$ and $s$ are the arm number, diameter and spacing of the transverse reinforcement, $f_{y w}$ is the yield strength of the transverse reinforcement, which is in the range of $414 \mathrm{MPa}$ to 541 $\mathrm{MPa} ; f_{y}$ is the yield strength of the longitudinal reinforcement, which ranges from $452 \mathrm{MPa}$ to $491 \mathrm{MPa}$; and $\rho$ is the longitudinal reinforcement ratio, which is in-between 0.0140 and 0.0473 .

\section{Finite element modeling}

FEA has been accomplished using the software ANSYS [32]. The analysis has been carried out using Newton-Raphson technique. A load-controlled analysis has been performed by increasing the load at the tip of the beam incrementally. The longitudinal and transverse reinforcements have been modeled as discrete reinforcements using Link8 elements. Rate independent multi-linear isotropic hardening option with von-Mises yield criterion has been used to define the material behaviour of reinforcement. The tensile stress-strain response of reinforcement based on the test data has been used in the present analysis. Perfect bond is a widely used simplification in the modeling approach, whereas in reality the bond behaviour is nonlinear. Lin and Zhang [33] stated that the predictions from a finite element model assuming both perfect bonding and bond-slip effect agree well with the experimental results and the deviation after cracking is limited. It can be inferred from the test results [30,31] that there was no bond-slip failure; hence a perfect bond is assumed between the reinforcement and the concrete components.

Solid45 elements have been used at the supports and at the loading regions to prevent stress concentrations. This element has eight-nodes with three degrees of freedom at each node. The concrete has been modelled using Solid65 eight-node brick element, which is capable of simulating the cracking and crushing behavior of brittle materials. The crack interface shear transfer coefficient for open cracks is assumed to take a value of 0.5 while it is assumed to take a value of 0.9 for closed cracks. The Solid65 element requires isotropic material properties to properly model the concrete. The Drucker-Prager yield criterion for concrete was used in the nonlinear FEA of the beams. The material constants of Drucker-Prager yield criterion are depending on the cohesion and internal friction angle, respectively. The internal friction angle is approximately between $30^{\circ}$ and $37^{\circ}$, which can be found by drawing various tangent lines to the compressive meridian, obtained from the experimental data of concrete. These values have been successfully used in the previous 


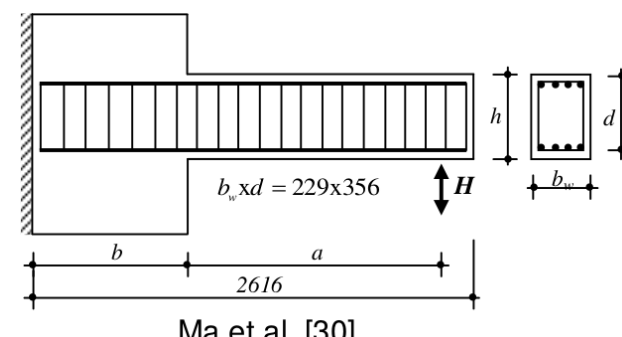

Ma et al. [30]

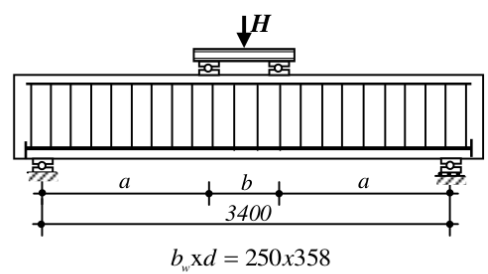

Rashid and Mansur [31]

Fig. 1. Test setups and geometric properties of beams (unit: $\mathrm{mm}$ )

Tab. 1. Geometrical and material properties of beams

\begin{tabular}{|c|c|c|c|c|c|c|c|}
\hline Beam name & $b(\mathrm{~mm})$ & $a(\mathrm{~mm})$ & $a / d$ & $f_{c}(\mathrm{MPa})$ & $\rho(\%)$ & $n_{s} \times \varphi_{s w} / s$ & $f_{y} ; f_{y w}(\mathrm{MPa})$ \\
\hline $\mathrm{R} 1^{a}$ & 826 & 1588 & 4.46 & 34.96 & 1.40 & $2 \times 6 / 89$ & $452 ; 414$ \\
\hline $\mathrm{R}^{a}{ }^{a}$ & 826 & 1588 & 4.46 & 28.89 & 1.40 & $2 \times 6 / 89$ & $452 ; 414$ \\
\hline $\mathrm{R}^{a}$ & 826 & 1588 & 4.46 & 31.58 & 1.40 & $4 \times 6 / 89$ & $452 ; 414$ \\
\hline $\mathrm{R} 4^{a}$ & 826 & 1588 & 4.46 & 30.20 & 1.40 & $4 \times 6 / 89$ & $452 ; 414$ \\
\hline $\mathrm{R}^{a}{ }^{a}$ & 1461 & 978 & 2.75 & 31.58 & 1.40 & $4 \times 6 / 89$ & $452 ; 414$ \\
\hline $\mathrm{R} 6^{a}$ & 826 & 1588 & 4.46 & 29.92 & 1.40 & $4 \times 6 / 89$ & $452 ; 414$ \\
\hline $\mathrm{A} 111^{b}$ & 1000 & 1200 & 3.36 & $42.80^{*}$ & 1.25 & $2 \times 10 / 200$ & $469 ; 541$ \\
\hline $\mathrm{A} 211^{b}$ & 1000 & 1200 & 3.36 & $42.80^{*}$ & 2.20 & $2 \times 10 / 200$ & $472 ; 541$ \\
\hline $\mathrm{B} 211^{b}$ & 1000 & 1200 & 3.36 & $74.60^{*}$ & 2.20 & $2 \times 10 / 200$ & $472 ; 479$ \\
\hline $\mathrm{B} 211 \mathrm{a}^{b}$ & 1000 & 1200 & 3.36 & $73.60^{*}$ & 2.20 & $2 \times 10 / 200$ & $472 ; 479$ \\
\hline $\mathrm{B} 311^{b}$ & 1000 & 1200 & 3.36 & $72.80^{*}$ & 3.46 & $2 \times 10 / 200$ & $472 ; 479$ \\
\hline $\mathrm{B} 312^{b}$ & 1000 & 1200 & 3.36 & $72.80^{*}$ & 3.46 & $2 \times 10 / 100$ & $472 ; 479$ \\
\hline $\mathrm{B} 321^{b}$ & 1000 & 1200 & 3.36 & $77.00^{*}$ & 3.46 & $2 \times 10 / 200$ & $472 ; 479$ \\
\hline${\mathrm{B} 331^{b}}^{2}$ & 1000 & 1200 & 3.36 & $72.80^{*}$ & 3.46 & $2 \times 10 / 200$ & $472 ; 541$ \\
\hline $\mathrm{B} 411^{b}$ & 1000 & 1200 & 3.36 & $77.00^{*}$ & 4.73 & $2 \times 10 / 200$ & $472 ; 479$ \\
\hline $\mathrm{C} 211^{b}$ & 1000 & 1200 & 3.36 & $85.60^{*}$ & 2.71 & $2 \times 10 / 200$ & $483 ; 541$ \\
\hline $\mathrm{C} 311^{b}$ & 1000 & 1200 & 3.36 & $88.10^{*}$ & 3.22 & $2 \times 10 / 200$ & $491 ; 541$ \\
\hline $\mathrm{C} 411^{b}$ & 1000 & 1200 & 3.36 & $85.60^{*}$ & 4.26 & $2 \times 10 / 200$ & $471 ; 541$ \\
\hline $\mathrm{C} 511^{b}$ & 1000 & 1200 & 3.36 & $88.10^{\star}$ & 5.31 & $2 \times 10 / 200$ & $478 ; 541$ \\
\hline $\mathrm{D} 211^{b}$ & 1000 & 1200 & 3.36 & $114.50^{*}$ & 2.20 & $2 \times 10 / 200$ & $472 ; 479$ \\
\hline $\mathrm{E} 211^{b}$ & 1000 & 1200 & 3.36 & $126.20^{*}$ & 2.20 & $2 \times 10 / 200$ & $472 ; 479$ \\
\hline
\end{tabular}

studies [34-36]. In this study, internal friction angles are considered as $33^{\circ}$ and $37^{\circ}$ for normal and high strength concrete, respectively.

In nonlinear FEA, a finer mesh leads to a weaker element with a premature failure, and the analysis does not reflect the actual load carrying capacity and deformational pattern [37]. In order to obtain realistic results from the numerical simulation of $\mathrm{RC}$ members avoiding the mesh dependency problem, optimum mesh size is used. The explanation for the optimum mesh size is given in Koksal and Arslan [37] and can be defined in two different ways as given by Bedard and Kotsovos [38] and Bazant and Oh [39]. Based on these studies, the representative size should ideally be taken as two or three times the maximum aggregate size in the case of the concrete. In this study, optimum mesh size was chosen as four times the maximum aggregate size, which is the same as in the studies of Arslan [35] and Arslan and Hacisalihoglu [36].

The tensile strength $f_{t}$ of concrete is taken as $0.3 f_{c}^{2 / 3}$ [40]. The direct tensile strength of concrete is assumed as $f_{t}=$ $0.3 f_{c}^{2 / 3}$ and the modulus of elasticity $E_{c}$ is taken as $4700 \sqrt{f_{c}}[2]$ for normal strength concrete and $E_{c}=3320 \sqrt{f_{c}}+6900(\mathrm{MPa})$ for high strength concrete [41].

\section{Evaluation of FEA Results}

The load-deflection curves obtained via experiments and FEA for the beams are shown in Fig. 2[7]. The load-deflection curves of analysed beams were obtained under one-way loadings, while the experiments were carried out under reversedcyclic loading. Consequently, the strength degradation due to the hysteretic loading could not be captured for the R1-R6 beams.

The FEA results are compared with the results of experimental studies selected from literature, and it is observed that the lateral load-deflection curves of analysed beams are in reasonable agreement with the experimental results. The numerical load-deflection curves were obtained through a one-way static procedure. On the other hand, the test was carried out under cyclic loading for Ma et al.'s [30] beams and monotonic loading for Rashid and Mansur's [31] beams. For this reason, the experimental curves under negative loads are removed from the 

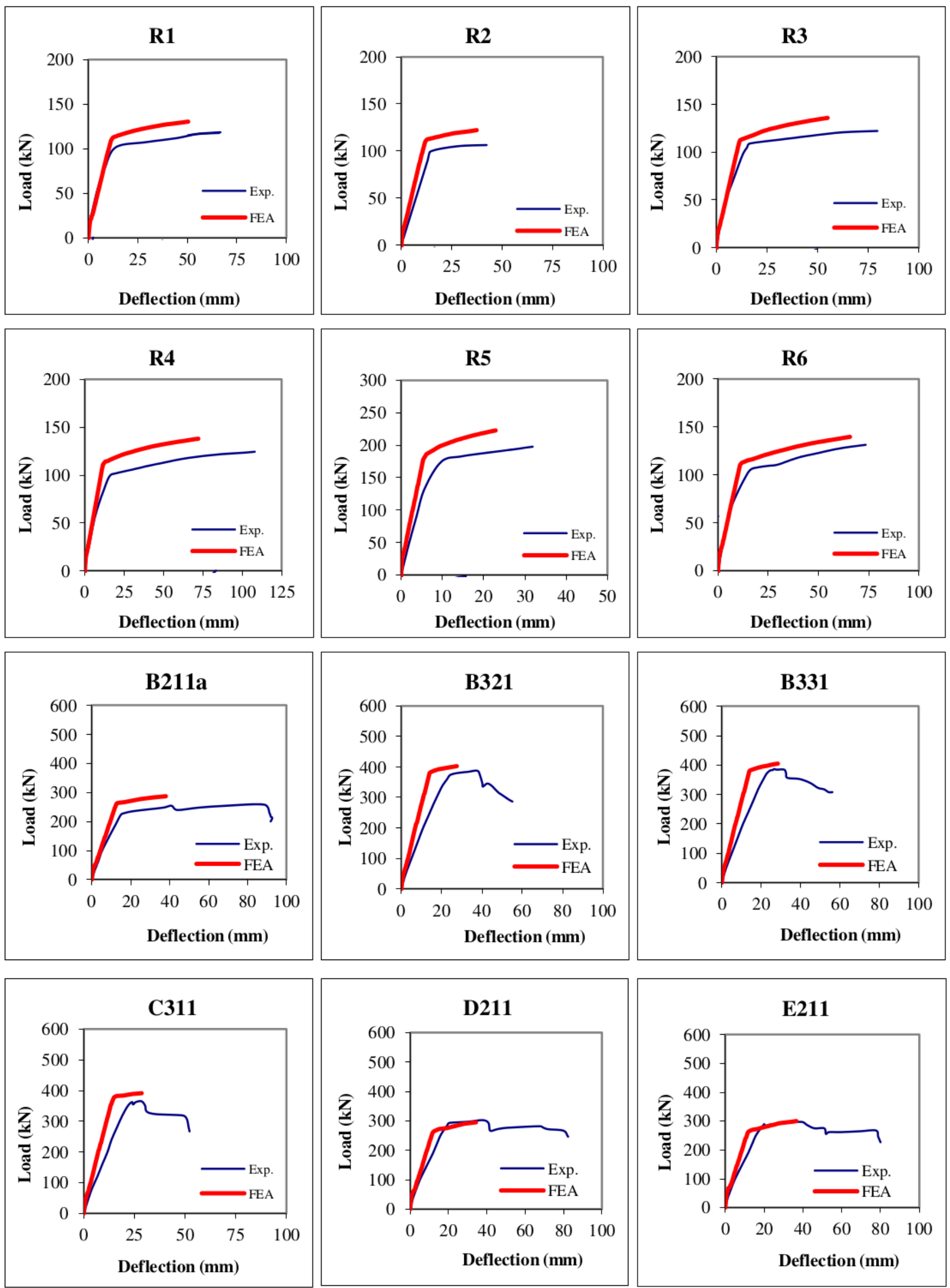

Fig. 2. Experimental and numerical load-deflection curves 
figures. Furthermore, actual geometrical and material properties were used in the analyses, however it is possible that there may be discrepancies between the properties of material samples and beams, and the differences in the initial branches may result from the measurement sensitivity in the experiments.

The yielding occurs when the mean value of all shearing stresses reach a critical value that linearly depends on the hydrostatic stress. The failure occurs when the Drucker-Prager cone crosses the surface. By failure, it is meant either the actual failure caused by unstable crack growth or the onset of softening material response, with the localization of deformation into a shear band.

\subsection{Concrete contribution to shear strength}

Flexural cracks cause a degradation of the shear strength since they cannot resist shear forces [7]. In this study, "transverse reinforcement strength component", $v_{s}$, is estimated from the transverse reinforcement stress at the maximum load. Once the transverse shear strength of the beams and the transverse reinforcement strength component are obtained, "concrete contribution to shear strength", $v_{c}$, can be calculated as in the other studies [5-7] (Table 2).

$$
v_{c}=v-v_{s}
$$

Tab. 2. Shear strengths of beams using FEA

\begin{tabular}{|c|c|c|c|}
\hline \multirow{2}{*}{ Beam name } & $v(M P a)$ & $v_{s}(M P a)$ & $v_{c}(M P a)$ \\
\hline & $((1))$ & (2) & $(\sqrt{1})-(\sqrt{2})$ \\
\hline $\mathrm{R} 1^{a}$ & 1.61 & 0.74 & 0.87 \\
\hline $\mathrm{R}^{a}{ }^{a}$ & 1.50 & 0.63 & 0.88 \\
\hline $\mathrm{R}^{a}$ & 1.67 & 1.18 & 0.49 \\
\hline $\mathrm{R}^{a}{ }^{a}$ & 1.70 & 1.21 & 0.49 \\
\hline $\mathrm{R}^{a}$ & 2.74 & 1.79 & 0.95 \\
\hline $\mathrm{R}^{a}$ & 1.72 & 1.12 & 0.60 \\
\hline $\mathrm{A} 111^{b}$ & 1.99 & 0.72 & 1.27 \\
\hline $\mathrm{A} 211^{b}$ & 3.07 & 1.07 & 2.00 \\
\hline $\mathrm{B} 211^{b}$ & 3.28 & 0.97 & 2.31 \\
\hline $\mathrm{B} 211 \mathrm{a}^{b}$ & 3.21 & 0.81 & 2.40 \\
\hline $\mathrm{B} 311^{b}$ & 4.48 & 1.31 & 3.17 \\
\hline $\mathrm{B}_{12}{ }^{b}$ & 4.48 & 1.57 & 2.91 \\
\hline $\mathrm{B} 321^{b}$ & 4.50 & 1.37 & 3.13 \\
\hline${\mathrm{B} 331^{b}}$ & 4.53 & 1.14 & 3.39 \\
\hline $\mathrm{B} 411^{b}$ & 5.66 & 1.32 & 4.34 \\
\hline $\mathrm{C} 211^{b}$ & 3.78 & 1.00 & 2.78 \\
\hline $\mathrm{C} 311^{b}$ & 4.38 & 1.29 & 3.09 \\
\hline $\mathrm{C} 411^{b}$ & 5.31 & 1.40 & 3.92 \\
\hline $\mathrm{C} 511^{b}$ & 6.43 & 1.70 & 4.73 \\
\hline $\mathrm{D} 211^{b}$ & 3.30 & 0.33 & 2.97 \\
\hline $\mathrm{E} 211^{b}$ & 3.36 & 0.26 & 3.10 \\
\hline & & & 31 \\
\hline
\end{tabular}

5.2 Influence of displacement ductility on the concrete contribution to shear strength

Based on FEA results, depending on displacement ductility of $\mathrm{RC}$ beams, the relative concrete contribution to shear strength varies. Design Codes [2, 4, 25, 40] tend to be excessively conservative and the contribution of the concrete to the shear strength is either neglected or considered based on the enhancement in the flexural capacities of beam and column. However, the fact that this approach is independent of the attained ductility level results in unconservative values of $v_{c}$ at high levels of deformation [26].

The resulting normalized concrete contribution, $v_{c} / \sqrt{f_{c}}$, versus displacement ductility is plotted in Fig. 3 The FEA performed here indicates that the $v_{c} / \sqrt{f_{c}}$ of beams decreases with increasing displacement ductility $\left(\delta_{u} / \delta_{y}\right)$ demand. A regression analysis is undertaken to identify the influence of $\delta_{u} / \delta_{y}$ on $v_{c}$ using the results of FEA. The variation of the numerical $v_{c}$ with $f_{c}$ and $\delta_{u} / \delta_{y}$ can be expressed as follows,

$$
v_{c}=0.68\left(\frac{\delta_{u}}{\delta_{y}}\right)^{-1.03} \sqrt{f_{c}}
$$

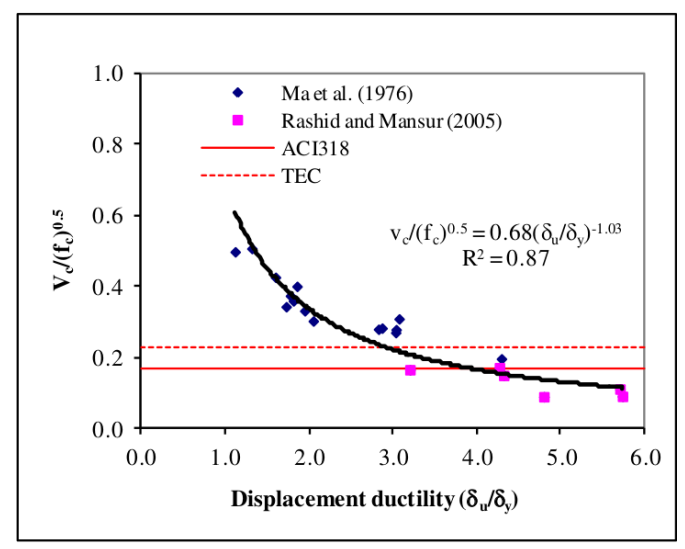

Fig. 3. Influence of displacement ductility on $v_{c}$ at collapse state

Eq. (16) clearly shows that the $v_{c} / \sqrt{f_{c}}$ is expressed as a function of $\left(\delta_{u} / \delta_{y}\right)^{-1.03}$. The effect of $\delta_{u} / \delta_{y}$ on the $v_{c} / \sqrt{f_{c}}$ is illustrated in Fig. 3, which shows that the proposed equation matches closely enough with the numerical results.

Based on the results of FEA and considering the influence of $\delta_{u} / \delta_{y}$ on the concrete contribution to shear strength, shear strength of RC beams can be expressed as:

$$
v_{n}=0.68\left(\frac{\delta_{u}}{\delta_{y}}\right)^{-1.03} \sqrt{f_{c}}+0.40 \rho_{s} f_{y w}
$$

The solid and dashed lines in Fig. 3 show the values of $v_{c} / \sqrt{f_{c}}$ against $\delta_{u} / \delta_{y}$ given by design codes ACI318 [2] and TEC [4], based on TS500 [20] prediction, respectively. A higher $\delta_{u} / \delta_{y}$ results in less concrete shear contribution capacity. Based on FEA results, two different $\delta_{u} / \delta_{y}$ limits may be expressed for ACI318 [2] and TEC [4]. The concrete contribution to shear strength can be decreased if $\delta_{u} / \delta_{y}$ exceeds 3 for TEC [4]. Sim- 
Tab. 3. Comparison of shear strength predictions using FEA results

\begin{tabular}{|c|c|c|c|c|c|c|c|}
\hline Prediction & MV & SD & CV & Prediction & MV & SD & CV \\
\hline$v_{c, F E A} / v_{c, \text { prop }}$ & 1.028 & 0.195 & 0.190 & $v_{n, F E A} / v_{n, p r o p}$ & 1.141 & 0.151 & 0.132 \\
\hline$v_{c, F E A} / v_{c, A C I}$ & 1.681 & 0.743 & 0.442 & $v_{n, F E A} / v_{n, A C I}$ & 1.104 & 0.447 & 0.405 \\
\hline$v_{c, F E A} / v_{c, E C 8-3}$ & 2.626 & 0.660 & 0.251 & $v_{n, F E A} / v_{n, E C 8-3}$ & 1.479 & 0.258 & 0.174 \\
\hline$v_{c, F E A} / v_{c, \text { Aschheim }}$ & 1.481 & 1.070 & 0.722 & $v_{n, F E A} / v_{n, \text { Aschheim }}$ & 1.156 & 0.261 & 0.226 \\
\hline$v_{c, F E A} / v_{c, \text { Priestly }}$ & 1.313 & 0.291 & 0.221 & $v_{n, F E A} / v_{n, \text { Priestly }}$ & 0.930 & 0.241 & 0.260 \\
\hline$v_{c, F E A} / v_{c, \text { Perez }}$ & 3.600 & 1.645 & 0.457 & $v_{n, F E A} / v_{n, \text { Perez }}$ & 1.409 & 0.642 & 0.456 \\
\hline$v_{c, F E A} / v_{c, F E M A}$ & 2.153 & 0.619 & 0.288 & $v_{n, F E A} / v_{n, F E M A}$ & 1.209 & 0.443 & 0.367 \\
\hline$v_{c, F E A} / v_{c, \text { Kowalsky }}$ & 1.146 & 0.267 & 0.233 & $v_{n, F E A} / v_{n, \text { Kowalsky }}$ & 0.892 & 0.266 & 0.298 \\
\hline$v_{c, F E A} / v_{c, \text { Sezen }}$ & 2.027 & 0.625 & 0.308 & $v_{n, F E A} / v_{n, S e z e n}$ & 1.227 & 0.375 & 0.305 \\
\hline$v_{c, F E A} / v_{c, \text { Howser }}$ & 1.370 & 0.524 & 0.383 & $v_{n, F E A} / v_{n, \text { Howser }}$ & 0.952 & 0.264 & 0.277 \\
\hline
\end{tabular}

MV: Mean value, SD: Standard deviation, CV: Coefficient of variation

ilarly, the concrete contribution to shear strength can be decreased if $\delta_{u} / \delta_{y}$ exceeds 4 for ACI318 [2]

\section{Evaluation of proposed equation}

Table 3 summarizes the comparisons of the concrete contribution to shear strength, $v_{c}$, and shear capacity, $v_{n}$, predictions obtained from the proposed equation, ACI318 [2], TEC [4], EC8-3 [25], FEMA356 [28], Aschheim's equation [9], Priestley's equation [10], Perez's equation [13], Kowalsky's equation [29], Sezen's equation [15], Howser's equation [16] with the FEA results. The predictions by the proposed equation for the concrete contribution to shear strength of beams are relatively better, whereas ACI318, Sezen's equation, FEMA prediction, and Perez's equation is excessively conservative for most of the FEA results and the shear strength predictions of beams are also relatively better, whereas Perez's equation is excessively conservative for most of the FEA results.

\section{Conclusions}

Considering that the results of nonlinear FEA on RC beams are in agreement with the experimental results, the following conclusions can be drawn:

- The results of numerical analyses indicate that the normalized concrete contribution $\left(v_{c} / \sqrt{f_{c}}\right)$ of RC beams degrades with increasing displacement ductility demand.

- It can be seen that the proposed $v_{c}$ and $v_{n}$ predictions for RC beams result in the lowest $\mathrm{CV}$ for the ratio of FEA results to the predicted value. Hence Eq. (16) and Eq. (17) provides better results than four codes of practice and six equations proposed by different researchers for the predictions of $v_{c}$ and $v_{n}$. It is to be noted that the proposed equations are based on a limited amount of data.

- For ACI318 and TS500, two different displacement ductility limits may be expressed. The concrete contribution to shear strength can be decreased if displacement ductility exceeds 3 for TS500 and 4 for ACI318.

\section{References}

1 Biskinis DE, Roupakias GK, Fardis MN, Degradation of shear strength of RC members with inelastic cyclic displacements, ACI Structural Journal, 101(6), (2007), 773-783, DOI $10.14359 / 13452$

2 ACI Committee 318, Building Code Requirements for Structural Concrete, American Concrete Institute; Farmington Hills, MI, 2011.

3 CSA A23.3-04, Concrete design handbook, Canadian Standards Association; Ottawa, Ont, 2006.

4 Turkish Earthquake Code, Specification for Structures to be Built in Disaster Areas, Ministry of Public Works and Settlement Government of Republic of Turkey; Ankara, 2007.

5 Arslan G, Polat Z, Contribution of concrete to shear strength of RC beams failing in shear, Journal of Civil Engineering and Management, 19(3), (2013), 400-408, DOI 10.3846/13923730.2012.757560

6 Arslan G, Hacısalihoglu M, Balcı M, Borekci M, An investigation on seismic design indicators of RC columns using finite element analyses, International Journal of Civil Engineering, 12(2), (2014), 237-243.

7 Arslan G, Kiristioglu I, Shear degradation of reinforced concrete beams, European Journal of Environmental and Civil Engineering, 17(7), (2013), 554-563, DOI $10.1080 / 19648189.2013 .799442$

8 Ang BG, Priestley MJN, Paulay T, Seismic shear strength of circular reinforced concrete columns, ACI Structural Journal, 86(1), (1989), 45-59, DOI $10.14359 / 2634$

9 Aschheim M, Moehle JP, Shear strength and deformability of RC bridge columns subjected to inelastic displacements, UCB/EERC 92/04, University of California; Berkeley, 1992.

10 Priestley MJN, Verma R, Xiao Y, Seismic shear strength of reinforced concrete columns, Journal of Structural Engineering, 120(8), (1994), 2310-2329, DOI 10.1061/(asce)0733-9445(1994)120:8(2310)

11 Lehman DE, Lynn AC, Aschheim MA, Moehle JP, Evaluation methods for reinforced concrete columns and connections, In: Proc. 11th World Conf. on Earthquake Engineering; 673, Elsevier Science Ltd., Acapulco, Mexico, 1996.

12 ATC32, Improved Seismic Design Criteria for California Bridges: Provisional Recommendations, Applied Tech. Council; Redwood City, CA, USA, 1996.

13 Perez BM, Pantazopoulou SJ, Mechanics of concrete participation in cyclic shear resistance of $R C$, Journal of Structural Engineering, 124(6), (1998), 633-641, DOI 10.1061/(asce)0733-9445(1998)124:6(633)

14 FEMA273, NEHRP guidelines for the seismic rehabilitation of buildings. Publication, Federal Emergency Management Agency; Washington D.C., 1997.

15 Sezen H, Moehle JP, Shear strength model for lightly reinforced concrete 
columns, Journal of Structural Engineering, 130(11), (2004), 1692-1703, DOI 10.1061/(asce)0733-9445(2004)130:11(1692)

16 Howser R, Laskar A, Mo YL, Seismic Interaction of Flexural Ductility and Shear Capacity in Normal Strength Concrete, Final Report, Department of Civil and Environmental Engineering, University of Houston; Houston, Texas, 2007.

17 Lee J Y, Watanabe F, Shear deterioration of reinforced concrete beams subjected to reversed cyclic loading, ACI Structural Journal, 100(4), (2003), 480-489, DOI $10.14359 / 12657$

18 Elwood KJ, Moehle JP, Axial capacity model for shear-damaged columns, ACI Structural Journal, 102(4), (2005), 578-587, DOI $10.14359 / 14562$

19 ASCE-ACI426, The shear strength of reinforced concrete members, Proc ASCE 99(ST6), (1973), 1091-1187.

20 TS-500, Requirements for Design and Construction of Reinforced Concrete Structures (in Turkish), Turkish Standards Institute; Ankara, Turkey, 2000.

21 NZS3101, Concrete Structures Standard; Wellington, New Zealand, 2006.

22 Bousias SN, Verzeletti G, Fardis MN, Guiterrez E, Load-path effects in column biaxial bending with axial force, Journal of Structural Engineering, 121(5), (1995), 596-605, DOI 10.1061/(asce)0733-9399(1995)121:5(596)

23 Acun B, Sucuoglu $\mathbf{H}$, Energy dissipation capacity of reinforced concrete columns under cyclic displacements, ACI Structural Journal, 109(4), (2012), 531-540, DOI $10.14359 / 51683872$

24 Park HG, Yu EJ, Choi KK, Shear-strength degradation model for $R C$ columns subjected to cyclic loading, Engineering Structures, 34, (2012), 187-197, DOI $10.1016 /$ j.engstruct.2011.08.041

25 Eurocode 8, Design of Structures for Earthquake Resistance Part 3: Assessment and Retrofitting of Buildings, European Committee for Standardization; Brussels, Belgium, 2005.

26 Eurocode 8, Design of Structures for Earthquake Resistance Part 1: General rules, seismic actions and rules for buildings, European Committee for Standardization; Brussels, Belgium, 2004.

27 Perez BM, Pantazopoulou SJ, A study of the mechanical response of reinforced concrete to cyclic shear reversals, 11th world Conference on earthquake engineering, 1996.

28 FEMA356, Prestandart and Commentary for The Seismic Rehabilitation of Buildings, Federal Emergency Management Agency; Washington D.C., 2000.

29 Kowalsky MJ, Priestley MJN, Improved analytical model for shear strength of circular reinforced concrete columns in seismic regions, ACI Structural Journal, 97(3), (2000), 388-396, DOI 10.14359/4633

30 Ma SY, Bertero V, Popov E, Experimental and analytical studies on the hysteretic behaviour of reinforced concrete rectangular and t-beams, Tech. Rep. UBC/EERC 76-2, University of California; Berkeley, 1976.

31 Rashid MA, Mansur MA, Reinforced high-strength concrete beams in flexure, ACI Structural Journal, 102(3), (2005), 462-471, DOI http://dx.doi.org/10.14359/14418

32 ANSYS User's Manual Revision 12.1, ANSYS Inc., 2010.

33 Lin X, Zhang YX, Bond-slip behaviour of FRP-reinforced concrete beams, Construction and Building Materials, 44, (2013), 110-117, DOI 10.1016/j.conbuildmat.2013.03.023

34 Chen WF, Plasticity in Reinforced Concrete, McGraw-Hill; NY, 1982.

35 Arslan G, Sensitivity study of the Drucker-Prager modeling parameters in the prediction of the nonlinear response of reinforced concrete structures, Materials \& Design, 28(10), (2007), 2596-2603, DOI 10.1016/j.matdes.2006.10.021

36 Arslan G, Hacisalihoglu M, Nonlinear analysis of RC columns using the Drucker-Prager model, Journal of Civil Engineering and Management, 19(1), (2013), 69-77, DOI 10.3846/13923730.2012.734858

37 Koksal HO, Arslan G, Damage analysis of RC beams without web reinforcement, Magazine of Concrete Research, 56(4), (2004), 231-241, DOI 10.1680/macr.2004.56.4.231
38 Bedard C, Kotsovos MD, Fracture process of concrete for NLFEA methods, ASCE Journal of Structural Engineering, 112(3), (1986), 573-586, DOI 10.1061/(ASCE)0733-9445(1986)112:3(573)

39 Bazant ZP, Oh B, Crack band theory for fracture of concrete, Materiaux et Constructions, 16(3), (1983), 155-177, DOI 10.1007/BF02486267

40 Eurocode 2, Design of Concrete Structures Part 1: General Rules and Rules for Buildings, European Committee for Standardization; Brussels, Belgium, 2004.

41 ACl Committee 363, Guide to Quality Control and Testing of High Strength Concrete, American Concrete Institute; Farmington Hills, MI, 1998. 